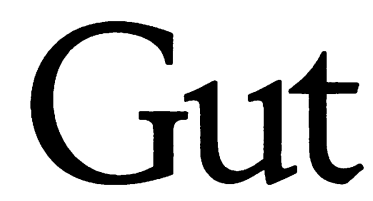

Leading article

\title{
Vitamin C and gastric cancer: supplements for some or fruit for all?
}

The concept that vitamin $\mathrm{C}$ can prevent disease has an enduring appeal. This is perhaps not surprising given the variety of different metabolic functions with which the vitamin is involved ${ }^{1}$ and the observations that Homo sapiens is one of the few mammalian species unable to synthesise it de novo. Present interest is focused on its possible role in cancer prevention and in particular, the prevention of gastric cancer.

The epidemiological evidence concerning vitamin $C$ and gastric cancer has been the subject of several excellent reviews. ${ }^{2-4}$ The link between high fruit consumption and a low gastric cancer incidence seems well founded. But fruit contains many substances in addition to vitamin $\mathrm{C}$ that may be relevant to cancer prevention, in particular $\beta$-carotene which may be an anti-carcinogen in its own right. ${ }^{5}$ When individual nutritional elements of the diet are taken separately, the association with reduced cancer risk remains strong for vitamin $C^{26}$ but proof that it is the 'active ingredient' is difficult because even plasma ascorbic acid concentrations are at best a modest indication of whole body vitamin $\mathrm{C}$ status. ${ }^{7}$ Epidemiological correlations do not always translate into successful disease prevention strategies. The failure of a number of vitamin supplementation studies, most notably the Finnish lung cancer prevention study, ${ }^{8}$ shows the dangers of drawing simplistic conclusions from epidemiological data in diseases with complex aetiologies.

Justification for pursuing the vitamin $C$ hypothesis in relation to gastric cancer was supported by two important reports from the gastroenterology group at Leeds. They showed that, provided plasma values are above a certain threshold, the normal stomach is able to concentrate vitamin $C$ in gastric juice to values many times higher than those in plasma and that most of this is in the reduced form ascorbic acid. ${ }^{10}$ Secondly they demonstrated that infection with Helicobacter pylori, considered by many to be a risk factor for gastric cancer, ${ }^{11-13}$ greatly depletes gastric juice ascorbic acid. ${ }^{14}{ }^{15}$ Similar low values are seen in other conditions that predispose to gastric cancer such as the post-surgical stomach or extensive gastric atrophy or intestinal metaplasia. ${ }^{16}$ Normal gastric juice seems to be endowed with a protective vitamin, which is lost in conditions of pre-malignant potential.
The remarkable activity of ascorbic acid as an antioxidant is most often quoted as the key function in cancer prevention. ${ }^{17}$ This derives from its ability to trap reactive oxygen metabolites (ROMs) and prevent propagation of the damaging chain reactions that result. Ascorbic acid is probably the most efficient ROM scavenger in biological fluids $^{18}$ and can act in synergy with vitamin $E$, which has similar functions in the lipid phase, ${ }^{19}$ reducing oxidised tocopherol back to its active form. The stomach is exposed to considerable oxidative stress, with ROMs arising from many sources, such as cigarette smoke and ingested toxins. ${ }^{20}$ The ROMs generated by the phagocytic activity of neutrophils and macrophages in $H$ pylori infected mucosa may be of particular importance. ${ }^{21}$ Oxidative stress has been implicated not only in the acute mucosal injury produced by these agents ${ }^{20} 2223$ but also in gastric carcinogenesis, ${ }^{23-25}$ where ROMs can act directly to produce DNA strand breaks, point mutations, and sister chromatid exchanges which, if not adequately repaired, may result in activation of oncogenes (or inactivation of tumour suppressor genes). ${ }^{26}$

How relevant is the presence of a ROM scavenger in the gastric juice? Most damaging radicals are generated within the mucosa and probably act locally. Those occurring in the juice are unlikely to exert much effect on the epithelial cells. $^{27}$ The hydroxyl radical, the most reactive and damaging of the radicals that vitamin $\mathrm{C}$ is able to scavenge, can act over very short (nanometer) distances ${ }^{28}$ and is unlikely to penetrate the gastric mucus layer, which is itself an effective ROM scavenger. ${ }^{29}$ Perhaps the high concentration of vitamin $C$ within the mucosa itself ${ }^{930}$ is more relevant to protection against oxidative damage than that in the surrounding gastric juice.

The interactions of vitamin $\mathrm{C}$ and transition metals are also complex. In aqueous solution a combination of ascorbic acid and even trace amounts of iron, leads to the production of ROMs rather than their removal. ${ }^{28}$ The importance of iron in mediating ROM damage to gastric cells has been amply shown in in vitro culture. ${ }^{20}$ The availability of iron within cells is limited by sequestration into ferritin where it is unable to participate in ROM generating reactions. ${ }^{31}$ However, ascorbic acid may be capable of liberating iron from ferritin. ${ }^{32}$ How the gastric 
epithelial cell with its high vitamin C content and susceptibility to iron mediated oxidative damage overcomes this problem is not known. The gastric mucosa seems different from other gastrointestinal epithelia by being uniquely impermeable to iron. ${ }^{33}$

The other property of ascorbic acid, of particular relevance to gastric cancer, is its ability to inhibit nitrosation $^{34}$ and the production of potentially mutagenic $N$-nitroso compounds (NOCs) in the stomach when nitrites (reduced from dietary nitrate) combine with other dietary nitrogen compounds (amides and amines). ${ }^{35}$ Ascorbic acid can inhibit NOC production in vivo $0^{36}$ and reduces the in vitro mutagenicity of gastric juice in a standard Salmonella typhimurium test. ${ }^{38}$ Direct measurement of NOCs in gastric juice has been beset by technical difficulties ${ }^{39}$ but Reed et al in Wexham Park Hospital, have recently developed a reliable assay. ${ }^{40}$ They have shown that although NOC formation can occur at the acidic $\mathrm{pH}$ found in the normal stomach, the highest concentrations are found in the stomach in hypochlorhydria where the reaction is catalysed in the presence of bacteria. The rate of acid catalysed nitrosation is dependent upon the nitrite concentration and may be more important in areas of the world with a high dietary nitrate intake. ${ }^{41}$ In such regions, the fall in gastric juice ascorbic acid that results from $H$ pylori infection might allow significant increases in NOC formation and contribute to the increased gastric cancer risk associated with the infection. Unfortunately, the only reliable measurements of gastric juice NOC are in patients from industrialised countries. Here, subjects with duodenal ulcers, in whom $H$ pylori infection can be assumed, have normal levels of NOCs. ${ }^{40}$ Bacteria catalysed nitrosation, associated with increased gastric juice $\mathrm{pH}$, may be quantitatively more important in areas where $H$ pylori prevalence is high, resulting in widespread gastric atrophy at an early age - and the source of excess NOC formation in patients from industrialised countries with an increased risk of gastric cancer because of gastric surgery or pernicious anaemia. ${ }^{42}$ In theory, there should be less potential for inhibition of nitrosation by ascorbic acid under these circumstances because vitamin $\mathrm{C}$ becomes unstable at higher $\mathrm{pH}$, being rapidly converted to the inactive oxidised form. ${ }^{43}$ Concentrations of vitamin $\mathrm{C}$ in the hypochlorhydric stomach are very low $^{10}$ and ascorbic acid disappears rapidly during in vitro incubation with gastric juice from patients with hypochlorhydria. ${ }^{10}$ Thus the stomach has largely lost its ability to maintain a high luminal concentration of ascorbic acid under those conditions most favourable for NOC formation. None the less, high dose vitamin $C$ supplements and fruit juices still seem capable of inhibiting gastric $N$-nitrosation in human volunteers with intraluminal pH above. ${ }^{41144}$

It seems unlikely that a mechanism for concentrating vitamin $\mathrm{C}$ in gastric juice has evolved solely to combat environmental agents to which humans have only been exposed for a short period of evolutionary history. The true evolutionary significance of the high vitamin $C$ content of gastric juice could lie not in cancer prevention but in the promotion of iron absorption. Absroption of therapeutic iron is increased when taken with vitamin $C,{ }^{45}$ provided the non-organic iron is in a soluble state and in its reduced $\left(\mathrm{Fe}^{2+}\right)$ form. ${ }^{46}$ Solubility is readily achieved by the acid $\mathrm{pH}$ in the stomach but is lost as soon as the stomach contents reach the duodenum unless iron is chelated to a carrier molecule. Although other chelators are available, ${ }^{47} 48$ ascorbic acid is ideally suited for this purpose and provides the added advantage of keeping the iron in a reduced state. ${ }^{46}$ The development of iron deficiency in prolonged hypochlorhydria or post-gastrectomy ${ }^{49}$ may be related to loss of ascorbic acid as a chelator rather than loss of gastric acid.
What are the prospects for ongoing studies of vitamin C supplementation in gastric cancer prevention? The results of the recently published Linxian projects ${ }^{50}$ were disappointing for vitamin $\mathrm{C}$ enthusiasts. Despite the inclusion of 30000 subjects in a region of very high gastric cancer prevalence and borderline nutritional deficiencies, vitamin C supplementation with twice the United States recommended daily allowance did not reduce the gastric cancer incidence or mortality. However, most cancers were of the diffuse type affecting the gastric cardia whose pathogenesis may be different. ${ }^{51}$ Furthermore, no attempt was made to eradicate $H$ pylori and it is known that vitamin $\mathrm{C}$ supplementation fails to increase gastric juice ascorbic acid concentrations to the same extent in the presence of persisting infection. ${ }^{30}$

Another possible explanation for the failure of this study is provided by a recent epidemiological study from Sweden. ${ }^{52}$ High dietary intake of vitamin C correlated with a reduced gastric cancer risk but the correlation was much stronger when ascorbic acid intake 20 years previously was considered rather than present diet. The histopathological progression towards gastric cancer proposed by Correa ${ }^{51}$ probably takes many years. If vitamin $C$ plays a protective part it may do so at an early stage, perhaps before gastric $\mathrm{pH}$ has increased as a result of extensive atrophy. If this is correct, then treatment with vitamin $C$ supplements in people already well advanced along the path to gastric cancer may be unsuccessful. A European multicentre study of vitamin $\mathrm{C}$ supplementation and $H$ pylori eradication in patients with gastric intestinal metaplasia ${ }^{53}$ is now in progress: its results are awaited with interest. In the meantime, rather than treating people with established risk factors with specific vitamin therapies, it might be better to follow the recommendations of the $\mathrm{WHO}^{54}$ and encourage an increase in fruit and vegetable consumption in the general population.

PAUL O'TOOLE MARTIN LOMBARD

Department of Medicine,

University of Liverpool,

PO Box 147,

Merseyside L69 3BX

1 Henson DE, Block G, Levine $M$. Ascorbic acid: biological functions and relation to cancer. $\mathcal{F}$ Natl Cancer Inst 1991; 83: 547-550.

2 Block G. Vitamin $\mathrm{C}$ and cancer prevention: the epidemiological evidence. Am f Clin Nutr 1991; 53: 270-82S

3 Negri E, Vecchia CL, Franceschi S, D'Avanzo B, Parazzini F. Vegetables and fruit consumption and cancer risk. Int $\mathcal{F}$ Cancer 1991; 48: 350-4.

4 Steinmetz KA, Potter JD. Vegetables, fruit and cancer. 1. Epidemiology. Cancer Causes Control 1991; 2: 325-57.

5 Bertram JS. Inhibition of chemically induced neoplastic transformation by carotenoids. Mechanistic studies. Ann NY Acad Sci 1993; 686: 161-75.

6 Chen J, Geissler C, Parpia B, Li J, Campbell TC. Antioxidant status and cancer mortality in China. Int $\mathcal{f}$ Epidemiol 1992; 21: 625-35.

7 Stähelin HB, Gey KF, Eichholzer M, Lüdin E, Bernasconi F, Thurneysen $\mathrm{J}$, et al. Plasma antioxidant vitamins and subsequent cancer mortality in the 12-year follow-up of the prospective Basel study. Am f Epidemiol 1991; 133: 766-75.

8 The Alpha-tocoperol, beta-carotene cancer prevention study group. The effect of vitamin $\mathrm{E}$ and beta-carotene on the incidence of lung cancer and other cancers in male smokers. $N$ Engl f Med 1994; 330: 1608-9.

9 Rathbone BJ, Johnson AW, Wyatt JI, Kelleher J, Heatley RV, Losowsky MS. Ascorbic acid: a factor concentrated in human gastric juice. Clin Sci 1989; 76: $237-41$.

10 Schorah CJ, Sobala GM, Sanderson M, Collis N, Primrose JN. Gastric juice ascorbic acid: effects of disease and implications for gastric ascorbic acid: effects of disease and implica

11 Forman D, Newell DG, Fullerton F, et al. Association between infection with HP and risk of gastric cancer: evidence from a prospective with $\mathrm{HP}$ and risk of gastric cancer:

12 Parsonnett J, Friedman GD, Vandersteen DP, et al. Helicobacter pylori infection and the risk of gastric carcinoma. $N$ Engl $f$ Med 1991; 325: infection

13 The Eurogast study group. An international association between Helicobacter pylori infection and gastric cancer. Lancet 1993; 341: 1359-62.

14 Sobala GM, Crabtree JE, Dixon MF, et al. Acute Helicobacter pylori infection: clinical features local and systemic immune response, gastric mucosal histology, and gastric juice ascorbic acid concentrations. Gut 1991; 32: 1415-8. 
15 Sobala GM, Schorah CJ, Shires S, et al. Effect of eradication of Helicobacter pylori on gastric juice ascorbic acid concentrations. Gut 1993; 34: $1038-41$.

16 Sobala GM, Pignatelli B, Schorah CJ, et al. Levels of nitrite, nitrate, $\mathrm{N}$-nitroso compounds, ascorbic acid and total bile acids in gastric juice of patients with and without precancerous conditions of the stomach. Carcinogenesis 1991; 12: 193-8.

17 Rose RC, Bode AM. Biology of free radical scavengers: an evaluation of ascorbate. FASEB F 1993; 7: 1135-42.

18 Frei B, England L, Ames BN. Ascorbate is an outstanding antioxidant in human blood plasma. Proc Natl Acad Sci 1989; 86: 6377-81.

19 Niki E. Interactions of ascorbate and $\alpha$-tocopherol. Ann NY Acad Sci 1987; 498: 186-99. 20 Hiraishi $\mathrm{H}$, Terano $\mathrm{A}$, Razandi $\mathrm{M}$, Sugimoto $\mathrm{T}$, Harada $\mathrm{T}$, Ivey $\mathrm{KJ}$. Role
of iron and superoxide in mediating hydrogen peroxide injury to cultured rat gastric cells. Gastroenterology 1993; 104: 780-8.

21 Davies GR, Banatvala N, Collins CE, et al. Relationship between infective load of HP and reactive oxygen metabolite production in antral mucosa. Scand $\mathcal{F}$ Gastroenterol 1994; 29: 419-24.

22 Rachmilewitz D, Karmeli F, Okon E, Samuni A. A novel antiulcerogenic stable radical prevents gastric mucosal lesions in rats. Gut 1994; 35: 1181-8.

23 Farinati F, Cardin R, Della Libera G, et al. Lipid peroxidation and antioxidant defences in human gastric mucosa: effect of Helicobacter pylori. Eur $\mathcal{F}$ Gastroenterol Hepatal 1993; 5 (suppl 2): s9-11.

24 Parsonnet J. Helicobacter pylori and gastric cancer. Gastroenterol Clin North Am 1993; 22: 89-104.

25 Correa P. Human gastric carcinogenesis: a multistep and multifactorial process. Cancer Res 1992; 52: 6735-40.

26 Fritsche $M$, Haessler C, Brandner G. Induction of nuclear accumulation of the tumour suppressor protein p 53 by DNA damaging agents. Oncogen 1993; 8: 307-18.

27 Nalini S. Balasubramanain KA. Effect of luminal exposure of oxidants on intestinal mucosal lipid peroxidation and absorptive function. Scand $\mathcal{F}$ Gastroenterol 1993; 28: 281-4.

28 Halliwell B, Gutteridge MC. Free radicals in biology and medicine. 2nd ed. Oxford: Clarendon Press, 1989.

29 Gong D, Turner B, Bhaskar KR, Lamont JT. Lipid binding to gastric mucin: protective effect against oxygen radicals. Am $¥$ Physiol 1990; 259: mucin: p

30 Waring A, Drake IM, Schorah C, Axon ATR, White K. Ascorbic acid concentrations in plasma, gastric juice and gastrointestinal mucosa. Effects of gastritis and oral supplementation. Gut 1994; 35: S19.

31 Balla G, Jacobs HS, Balla J, et al. Ferritin: A cytoprotective antioxidan strategem of endothelium. $\mathcal{F}$ Biol Chem 1992; 267: 18148-53.

32 Bienfait HF, van den Briel. Rapid mobilisation of ferritin iron by ascorbate in the presence of oxygen. Biochim Biophys Acta 1980; 631 507-10.

33 Dagg JH, Kuhn IN, Templeton MD, Finch CA. Gastric absorption of iron. Gastroenterology 1967; 53: 918-22.

34 Mirvish SS, Wallcave L, Eagan M, Shubik P. Ascorbate-nitrite reaction: possible means of blocking the formation of carcinogenic $N$-nitroso compounds. Science 1972; 177: 65-8.

35 Mirvish SS. Experimental evidence for inhibition of $\mathrm{N}$-nitroso compound formation as a factor in the negative correlation between vitamin $\mathrm{C}$ consumption and the incidence of certain cancers. Cancer Res 1994; 54: 1948-51s.
36 Sierra $\mathrm{R}$, Chinnock $\mathrm{A}$, Ohshima $\mathrm{H}$, et al. In vivo nitrosoproline formation and other risk factors in Costa Rican children from high- and low-risk areas for gastric cancer. Cancer Epidemiol Biomarkers Prev 1993; 2: 563-8.

37 Kryptopoulos SA, Pignatelli B, Karkanias G, Esteve J. Studies in gastric carcinogenesis $\mathrm{V}$. The effects of ascorbic acid on $\mathrm{N}$-nitroso compound formation in human gastric juice in vivo and in vitro. Carcinogenesis 1991, 12: $1371-6$.

38 O'Connor HJO, Habibzedah N, Schorah CJ, Axon ATR, Riley SE, Garner RC. Effect of increased intake of vitamin $\mathrm{C}$ on the mutagenic activity of gastric juice and intragastric concentrations of ascorbic acid. Carcinogenesis 1985; 6: 1675-6.

39 Hill MJ. Mechanisms of gastric carcinogenesis. Eur 7 Cancer Prev 1994; 3 (suppl 2): 25-9.

40 Reed PI, Xu GP, Li DH, Hill MJ, Johnston BJ. N-nitroso compounds levels in fresh gastric juice in relation to clinical diagnosis. Gut 1993; 34 (suppl 4): $S 30$.

41 Xu GP, Song PJ, Reed PI. Hypothesis on the relationship between gastric cancer and intragastric nitrosation: $\mathrm{N}$-nitrosamines in gastric juice of subjects from a high-risk area for gastric cancer and the inhibition of N-nitrosamine formation by fruit juices. Eur $f$ Cancer Prev 1993; 2: 25-36.

42 Reed PI, Haines K, Smith PLR, House FR, Walters CL. Gastric juice $\mathrm{N}$-nitrosamines in health and gastroduodenal disease. Lancet 1981; ii: 550-2.

43 Washko PW, Welch RW, Dhariwal KR, Wang Y, Levine M. Ascorbic acid and dehydroascorbic acid analyses in biological samples. Anal Biochem 1992; 204: 1-14

44 Reed PI, Johnston BJ, Walters CL, Hill MJ. Effect of ascorbic acid on the intragastric environment in patients at increased risk of developing gastric cancer. LARC Sci Publ 1991; 105: 139-42.

45 Brise H, Hallberg L. Effect of ascorbic acid on iron absorption. Acta Med Scand 1962; (suppl 376): 51-8.

46 Raja KB, Simpson RJ, Peters TJ. Investigation of a role for reduction in ferric iron uptake by mouse duodenum. Biochim Biophys Acta 1992; 1135: 141-6.

47 Wien EM, van Campen DR. Ferric iron absorption in rats: relationship to iron status, endogenous sulphydryl and other redox components in the intestinal lumen. $\mathfrak{F}$ Nutr 1991; 121: 825-31.

48 Conrad ME, Umbreit JN, Moore EG. A role for mucin in the absorption of inorganic iron and other metal cations. Gastroenterology 1991; 100: of inorgani.

49 Wheldon EJ, Vebables CW, Johnson IDA. Late metabolic sequelae of vagotomy and gastroenterostomy. Lancet 1970; i: 437-40.

50 Blot WJ, Li JY, Taylor PR, et al. Nutritional intervention trials in Linxian, China: supplementation with specific vitamin/mineral combinations, cancer incidence, and disease-specific mortality in the general population. f Natl Cancer Inst 1993; 85: 1483-91.

51 Correa P. A human model of gastric carcinogenesis. Cancer Res 1988; 48: 3554-60.

52 Hansson LE, Nyren O, Bergström R, et al. Nutrients and gastric cancer risk. A population-based case-control study in Sweden. Int $\mathcal{F}$ Cancer 1994; 57: 638-44.

53 Reed PI. ECP-IM intervention study. Eur $\mathcal{F}$ Cancer Prev 1994; 3 (suppl 2): 99-104.

54 National Research Council. Diet and health: implications for reducing chronic disease risk. Washington DC, USA: National Academy Press, 1990. 